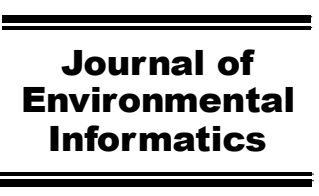

www.iseis.org/jei

\title{
Solving Water Quality Management Problem through Combined Genetic Algorithm and Fuzzy Simulation
}

\author{
T. Y. Xu ${ }^{1}$, and X. S. Qin ${ }^{1,2, *}$ \\ ${ }^{1}$ School of Civil \& Environmental Engineering, Nanyang Technological University, Singapore 639798 \\ ${ }^{2}$ DHI-NTU Water and Environment Research Centre and Education Hub, Nanyang Technological University, Singapore 639798
}

Received 17 December 2012; revised 7 May 2013; accepted 5 September 2013; published online 10 December 2013

\begin{abstract}
A combined genetic algorithm and fuzzy simulation approach (GAFSA) was developed through integrating fuzzy chance-constrained programming (FCCP) and genetic algorithm (GA) into a general optimization framework. The major advantage of GAFSA is that it could tackle generally-shaped fuzzy membership functions on both sides of the model constraints, rather than handle single special forms like triangular or trapezoidal. An agricultural water quality management problem that has been investigated by a number of previous studies was used to demonstrate the applicability of the proposed method. The results showed that GAFSA allowed violation of system constraints at specified possibilistic confidence levels, leading to model solutions with higher system benefits. A conservative planning scheme could bring a more reliable system, but would be less economically attractive. Conversely, planning towards a higher system benefit would lead to a higher risk of system failure. The proposed model could help agricultural water managers analyse the trade-off between the overall system benefit and the failure risk of environmental compliance. A comparison of GAFSA to FCCP was given, and the potential limitations of the proposed method were also discussed.
\end{abstract}

Keywords: fuzzy chance-constrained programming, genetic algorithm, effluent control management, agricultural system, uncertainty

\section{Introduction}

For many decades, agriculture has focused on adopting new technologies or improving existing farming practices for boosting production which leads to many environmental problems, such as the soil erosion, non-point sources pollution, and water shortage (Huang, 1996). These problems have been associated with both water quantity and water quality, and urged planners to develop a comprehensive management strategy. However, the agricultural water quality management system is complicated with a variety of uncertainties derived from many factors such as economic objective, environmental requirement, and policy regulation (Huang and Xia, 2001). Therefore, effective decision-support tools with the capability of tackling uncertainties are desired to be developed.

Over the past years, a large number of inexact optimization techniques have been applied to deal with uncertainties associated with water quality management systems. Most of these methods were related to fuzzy mathematical programming (FMP), stochastic mathematical programming (SMP), and interval linear programming (ILP) (Beck, 1987; Cardwell and Ellis, 1993; Nie et al., 2007; Rong and Lahdelma, 2008; Rehana

\footnotetext{
${ }^{*}$ Corresponding author. Tel.: +65 6790 5288; fax: +65 67921650 .

E-mail address: xsqin@ntu.edu.sg (X. S. Qin).
}

ISSN: 1726-2135 print/1684-8799 online

(C) 2013 ISEIS All rights reserved. doi:10.3808/jei.201300244 and Mujumdar, 2009; Aviso et al., 2010; Lv et al., 2010; Fan and Huang, 2012). Stochastic chance-constrained programming (SCCP) is one of the major methods of SMP, which offers a means of allowing the decision makers to consider objectives in terms of the probability of their attainment (Charnes and Cooper, 1959). The SCCP models were successfully applied in a number of environmental management problems (Wagner and Gorelick, 1987; Singh and Chakrabarty, 2011). Recently, it has been extended from stochastic to fuzzy environments (Liu and Iwamura, 1998). Fuzzy chance-constrained programming (FCCP) model is a novel FMP method, incorporating some predetermined confidence levels of fuzzy constraintssatisfaction into the models. Similar to SCCP model, the conventional technique of solving FCCP is to convert the fuzzy constraints to deterministic equivalents according to the predetermined confidence levels. Previously, applications of FCCP have been reported in many fields, including solid waste management (Huang et al., 1992) and water resources management (Guo and Huang, 2009; Li et al., 2009). However, in water quality management field, the related studies are very limited. Zhang et al. (2009) made the first attempt in applying a robust chance-constrained fuzzy possibilistic programming (RCFPP) model to water quality management in an agricultural system for providing decision schemes for different agricultural activities.

Nevertheless, most of the FCCP studies relied on techniques that were capable of dealing with fuzzy variables with special distributions, such as triangular and trapezoidal (Liu and 
Iwamura, 1998). In many real-world applications, the fuzzy parameters may have membership functions in various shapes. For example, in agricultural activities, the soil loss rate is affected by many factors such as crop type, climate condition, and soil profile; the on-site measurement data may lead to the generation of membership functions in complex shapes rather than simple triangular ones. Previously, few studies have addressed such a problem, particularly under the context of a FCCP framework.

Thus, the objective of this study is to develop a combined genetic algorithm and fuzzy simulation approach (GAFSA) for solving the fuzzy chance-constrained programming (FCCP) model for agricultural water quality management problem. Genetic algorithm (GA) is an adaptive heuristic search algorithm premised on the evolutionary ideas of natural selection and genetic. It will be used to solve a FCCP model with both sides being associated with fuzzy coefficients in varied shapes. GAFSA will be applied to an agricultural water quality management problem for demonstrating its applicability. Advantages and limitations of the proposed method will be further discussed.

\section{General Methodology}

\subsection{Fuzzy Chance-Constrained Programming}

Fuzzy chance-constrained programming (FCCP) was thoroughly discussed by Liu and Iwamura (1998). It allows incurporation of a set of predetermined confidence levels to the optimization framework, which reflects the degree of constraints satisfaction due to impacts of possibilistic uncertainties. A general FCCP model could be formulated as follows:

$$
\text { Minimize } f=C X
$$

Subject to:

$$
\begin{aligned}
& \operatorname{Pos}\{\tilde{A}, \tilde{B} \mid \tilde{A} X \leq \tilde{B}\} \geq \alpha \\
& D X \leq E \\
& C, A \neq 0 \\
& X \geq 0
\end{aligned}
$$

where $X$ is a vector of deterministic decision variables; $\tilde{A}$ and $\tilde{B}$ are vector items which are expressed as fuzzy sets with membership functions $\mu(\tilde{A})$ and $\mu(\tilde{B})$, respectively; $C, D$ and $E$ are vectors of deterministic auxiliary variables; $\operatorname{pos}\{\cdot\}$ denotes possibility of events in $\{\cdot\} ; \alpha$ is a predetermined confidence level. In model (1), Equation (1b) represents the fuzzy chance constraints with both side items being described as fuzzy sets. Other formulas are similar to those in a general deterministic model, including the objective function (1a), the general constraints (1c), the non-zero constraints (1d), and the general constraints (1e).

\subsection{Combined Genetic Algorithm and Fuzzy Simulation Approach (GAFSA)}

To solve model (1), the fuzzy chance constraints need be converted to their respective crisp equivalents. In many realworld applications, the fuzzy membership functions usually have specific shapes, such as exponential, Gaussian, triangular, and trapezoidal. Hence it is difficult to convert them to their respective deterministic equivalents unless they are all expressed in some special forms like triangular or trapezoidal (Liu and Iwamura, 1998). To solve this problem, we incorporate GA into a general FCCP model, and try to seek exact or approximate solution. Comparing to the conventional linear programming algorithms, GA relies on a penalty-based evaluation procedure and a number of directional searching algorithms (inspired by natural evolutions, such as initiation, mutation, selection, and crossover) to seek optimal model solutions.

Based on the concepts and techniques of possibility theory established by Zadeh (1978), Equation (1b) can be transformed into:

$$
\operatorname{Pos}\{\tilde{A}, \tilde{B} \mid \tilde{A} X \leq \tilde{B}\}=\operatorname{Sup}\left\{\min \mu_{\tilde{A}}(a), \mu_{\tilde{B}}(b) \mid a, b \in R, a \leq b\right\}
$$

Based on model (1), a general GAFSA model could be written as follows (Liu and Iwamura, 1998; Qin et al., 2010):

Minimize $F=C X+C P F+I P F$

Subject to:

$C P F=\left\{\begin{array}{l}0 \text { if } \operatorname{Pos}\{.\} \geq \alpha \text { is met } \\ \lambda_{1} \text { if } \operatorname{Pos}\{.\} \geq \alpha \text { is not met }\end{array}\right.$

$I P F=\left\{\begin{array}{l}0 \text { if } D X \leq E \text { is met } \\ \lambda_{2} \text { if } D X \leq E \text { is not met }\end{array}\right.$

$C, A \neq 0$

$X \geq 0$

where $F$ is a transformed objective function based on Equation (1a), which is convenient for GA to seek optimal solutions of model (3). According to Poojari and Varghese (2008) and Qin et al. (2010), $C P F$ in Equation (3b) is a penalty factor for describing the influence of fuzzy chance-constraints violation at a predetermined confidence level $\alpha ; \lambda_{1}$ is a large real number and can be used to quantitatively reflect the violation of fuzzy chance constraints. Similarly, $I P F$ in Equation (3c) is a penalty factor for reflecting the violation of deterministic constraints where $\lambda_{2}$ is a large real number. The values of $\lambda_{1}$ and $\lambda_{2}$ are much higher than the objective function values in order to get applicable solutions. As shown in model (3), it is important to calculate the possibilistic value of event $\{\cdot\}$. According to Liu and Iwamura (1998), a fuzzy-simulation-based iteration proce- 
ss can be used for such a purpose. The iteration process is described as follows:

(i) Take the hypercubes $A$ and $B$ containing $\alpha$-cut for both fuzzy numbers $\tilde{a}$ and $\tilde{b}$, and generate two crisp numbers $a$ and $b$. If $a X \leq b$, calculate $\mu_{\tilde{A}}(a)$ and $\mu_{\tilde{B}}(b)$ through the fuzzy membership functions and set $p=\min \left[\mu_{\tilde{A}}(a), \mu_{\tilde{B}}(b)\right]$.

(ii) Generate $a^{\prime}$ and $b^{\prime}$ satisfying $a^{\prime} X \leq b^{\prime}$ and obtain the corresponding $\mu_{\tilde{A}}\left(a^{\prime}\right)$ and $\mu_{\tilde{B}}\left(b^{\prime}\right)$. If $p<\min \left[\mu_{\tilde{A}}\left(a^{\prime}\right), \mu_{\tilde{B}}\left(b^{\prime}\right)\right]$, then set $p=\min \left[\mu_{\tilde{A}}\left(a^{\prime}\right), \mu_{\tilde{B}}\left(b^{\prime}\right)\right]$; otherwise, $p$ remains unchanged.

(iii) Repeat the above processes until a given number of cycle $n$ is reached. Finally, the maximum value $p$ will be regarded as the desired possibility to be determined. Finally, the model solution at a specific confidence level can be obtained.

Figure 1 shows some common fuzzy membership functions on both sides of the constraints. Generally, the fuzzy simulation approach is applicable as long as the fuzzy membership functions are given.
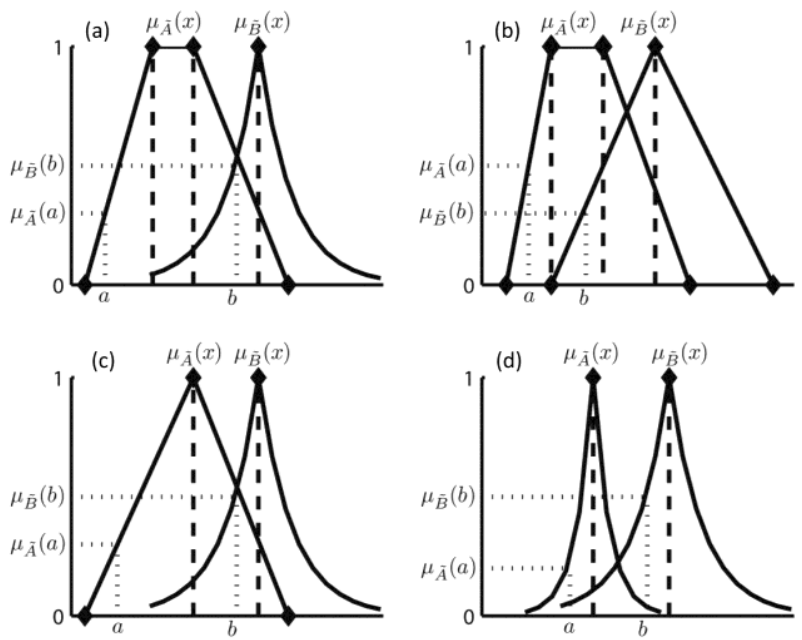

* (a) Trapezoidal vs. exponential shape; (b) trapezoidal vs. triangular shape; (c) triangular vs. exponential shape; (d) exponential vs. exponential shape

Figure 1. Common fuzzy membership functions on both sides of the constraints.

According to Equations (3b) and (3c), a compliance check is needed for both the uncertain and deterministic constraints for each potential solution (i.e. a chromosome) generated by GA iteration. Obviously, the best solution should fall within the solution pool without triggering any penalty of constraints violation. As the fuzzy simulation process is flexible on the shape of fuzzy variables, the proposed GAFSA framework is able to tackle complicated forms of fuzzy membership functions. As shown in Figure 2, the detailed procedures of GAFSA model are summarized as follows:

Step 1: Identify fuzzy uncertain variables and acquire the related fuzzy possibility distributions;

Step 2: Formulate a fuzzy chance-constrained programming model;

Step 3: Define the penalty factors of constraints satisfaction and build the fitness function based on model (3);
Step 4: Initiate the GA searching process, with each chromosome representing a potential model solution;

Step 5: Calculate the confidence levels of fuzzy chance-constraints satisfaction through the iteration-based fuzzy simulation;

Step 6: Evaluate the value of fitness function based on a predetermined confidence level;

Step 7: Check the stop criteria; if satisfied, generate the final solutions of $f_{o p t}$ and $X_{o p t}$; if not, proceed with standard GA operations of selection, crossover, and mutation, and go back to Step 4.

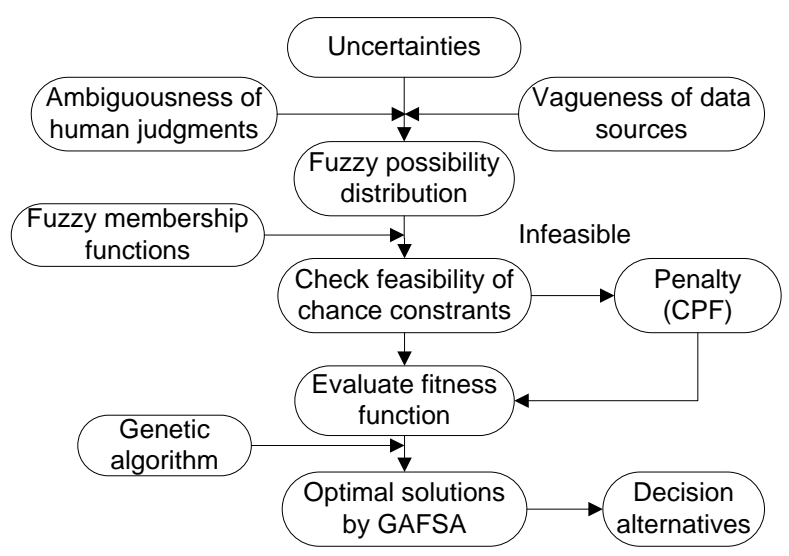

Figure 2. General framework of a GAFSA model.

\subsection{Example of Testing Effectiveness of GAFSA}

In order to test the effectiveness of GAFSA, a standard approach for solving triangular-shaped FCCP model proposed by Liu and Iwamura (1998) was used for comparison. A small numerical example is given as follows:

Maximize $f=3 x_{1}+x_{2}$

Subject to:

$(0.1,0.15,0.2) x_{1} \leq(0.95,1,1.05)$

$(0.1,0.25,0.3) x_{2} \leq(0.175,0.2,0.225)$

$0.25 x_{1}-0.3 x_{2} \leq 1$

$x_{1}, x_{2} \geq 0$

where the coefficient, like $(0.1,0.15,0.2)$ in Equation $(4 b)$, represents a triangular fuzzy set, where 0.1 and 0.2 are the lower and upper bounds of the fuzzy set, and 0.15 is the most likely value. Table 1 shows the comparison of solutions between GAFSA and FCCP. It shows that, at the same confidence level, the solutions obtained from GAFSA are close to those obtained from FCCP. It is also found that the GAFSA can only reach sub- 
optimal solutions. For example, at a confidence level of 0.6 , the objective value obtained from GAFSA (i.e. 17.02) is lower than that from FCCP (i.e. 17.08). Generally, GAFSA is capable of solving CCP model with fuzzy parameters on both sides of constraints and obtaining reasonable solutions.

Table 1. Comparison of Solutions between GAFSA and FCCP

\begin{tabular}{lllllll}
\hline \multirow{2}{*}{ Confidence level } & \multicolumn{2}{l}{ GAFSA } & \multicolumn{3}{l}{ FCCP } \\
\cline { 2 - 7 } & $x_{1}$ & $x_{2}$ & $f$ & $x_{1}$ & $x_{2}$ & $f$ \\
\hline 0.6 & 5.31 & 1.09 & 17.02 & 5.33 & 1.11 & 17.08 \\
0.7 & 5.21 & 1.01 & 16.63 & 5.21 & 1.01 & 16.66 \\
0.8 & 5.11 & 0.92 & 16.26 & 5.12 & 0.93 & 16.29 \\
0.9 & 5.03 & 0.85 & 15.94 & 5.03 & 0.86 & 15.96 \\
\hline
\end{tabular}

\section{Application in Agricultural Water Quality Management}

\subsection{Overview of the Study Case}

A hypothetical agricultural water quality management problem, which is adapted from Huang (1996) and Nie et al. (2008), will be used for demonstrating the applicability of the proposed GAFSA model. The model parameters are obtained from literatures based on representative cost/benefit and technical data (Tisdale and Nelson, 1966; Haith, 1982; Huang, 1996; Nie et al., 2008). The total tillable land of the study area is 96.4 ha. The main crops are wheat, vegetables and potato, and the main livestock are cattle, pig and poultry. The entire area was divided into three subareas, with the tillable land being 34.1, 23.9, and 40.4 ha, respectively. Irrigation water is withdrawn from three canals connected to a river flowing through the area. In this rural system, the crop cultivation and livestock breeding are two major ways to generate economic benefit. For detailed background information, readers are referred to Huang (1996) and Nie et al. (2008).

The hypothetical case is highly simplified and considers limited crops, livestock and nonpoint source losses. A realworld case is normally more complicated, involving more elements of soil pollution (e.g. chemical, biological and physical elements), governmental policies (e.g. labor requirement, land use restriction, product quality, and environmental standards), and agricultural activities (e.g. spraying, weeding and fertilizing). This could lead to the growth of model sizes and complexity of constraint considerations.

\subsection{Formulation of a GAFSA Model}

In this agricultural system, the nonpoint source losses of soil, nitrogen and phosphorus from fertilizer and manure have led to the pollution problems in the canal (Huang, 1996). The water contamination problem could decrease the amount of available water resources, and aggravate the water-shortage problems. This, in turn, would influence the crop cultivation and agricultural income. The decision makers are responsible for generating desired decision alternatives for agricultural activities and water usages based on the given objectives/restrictions, in order to maximize the total system benefit. Due to the features of vagueness and imprecision, parameters associated with environmental loading capacities (such as soil loss amounts from land planted to crop, allowable soil loss and pollutants discharge amounts) could be expressed by fuzz sets with various membership functions. This is deemed reasonable as, in practical applications, these data are normally difficult to be accurately defined or measured, and some empirical judgement or statistical analysis has to be made in order to quantify the related uncertainties. The distributions of these data could have large variations due to various reasons like spatial-temporal changes, climate impact, and data shortage; if fuzzy set theory is used to describe such uncertainties, the corresponding membership functions could hardly be fitted by simple forms like triangular shapes. For demonstration purpose, in this study, the soil loss rate from the land planted with crops and the maximum allowable soil loss rate are assumed as fuzzy sets with triangular and trapezoidal shapes, respectively. The maximum allowable soil-phase nitrogen and phosphorus loss rates are expressed as fuzzy sets in exponential forms (as shown in Table 2 and Figure 3 ). In reality, the procurement of the related information should rely on site survey, literature review, and expert consultations. Other deterministic model parameters are referred to Nie et al. (2008) and Xu and Qin (2010) (listed in Tables 2 and 3).
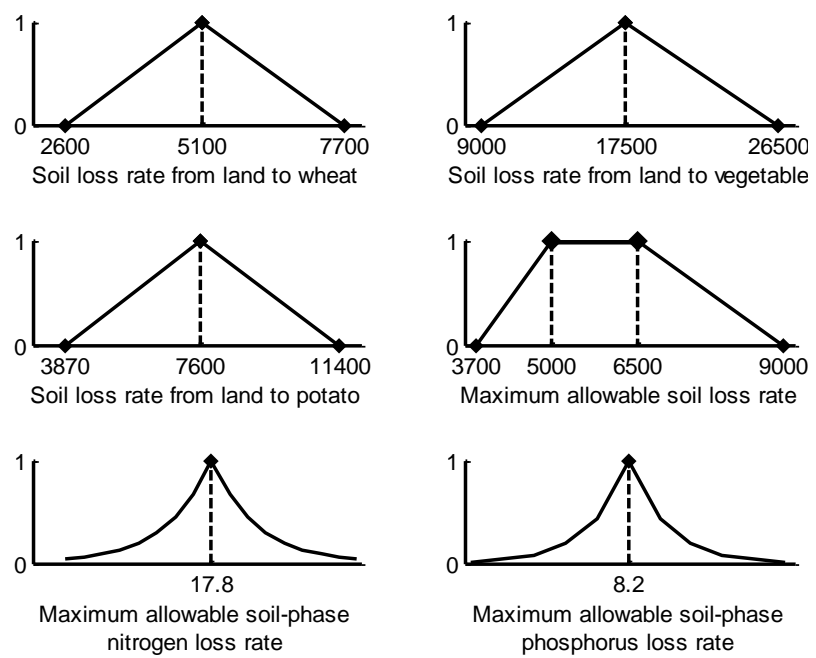

Figure 3. Fuzzy membership functions for fuzzy coefficients.

Hence, the model for agricultural effluent control could be formulated as follows (Nie et al., 2008; Xu and Qin, 2010):

$$
\begin{gathered}
\text { Maximize } f=\sum_{t=1}^{T} \sum_{i=1}^{I} \delta_{i} Y_{i} S_{i t}+\sum_{j=1}^{J} \eta_{j} Z_{j}-\sum_{t=1}^{T} \sum_{i=1}^{I} G_{i} S_{i t}-G_{M} \sum_{i=1}^{I} M_{i} \\
-G_{F} \sum_{i=1}^{I} F_{i}-\sum_{t=1}^{T} \sum_{i=1}^{I} v_{i t} W_{i t} S_{i t}+C P F+I P F
\end{gathered}
$$

Subject to:

$C P F=\left\{\begin{array}{l}0 \text { if } G(X, \xi) \text { is met } \\ \lambda_{1} \text { if } G(X, \xi) \text { is not met }\end{array}\right.$ 
Table 2. Model Parameters Related to Crops and Livestock

\begin{tabular}{|c|c|c|c|}
\hline \multirow{2}{*}{ Parameters related to crops } & Wheat & Vegetable & Potato \\
\hline & $(i=1)$ & $(i=2)$ & $(i=3)$ \\
\hline Unit yield of crop $i(\mathrm{~kg} / \mathrm{ha})$ & 6000 & 21500 & 15000 \\
\hline Dissolved nitrogen concentration in wet season runoff from the land planted with crop $i(\mathrm{mg} / \mathrm{l})$ & 1.5 & 2.7 & 2.2 \\
\hline Dissolved nitrogen concentration in dry season runoff from the land planted with crop $i(\mathrm{mg} / \mathrm{l})$ & 0.8 & 1.7 & 1.4 \\
\hline Dissolved phosphorus concentration in wet season runoff from the land planted with crop $i(\mathrm{mg} / \mathrm{l})$ & 0.15 & 0.26 & 0.23 \\
\hline Dissolved phosphorus concentration in dry season runoff from the land planted with crop $i(\mathrm{mg} / \mathrm{l})$ & 0.08 & 0.22 & 0.21 \\
\hline Unit nitrogen requirement of crop $i(\mathrm{~kg} / \mathrm{ha})$ & 105 & 155 & 100 \\
\hline Wet season runoff from the land planted with crop $i(\mathrm{~mm})$ & 65 & 82 & 86 \\
\hline Dry season runoff from the land planted with crop $i(\mathrm{~mm})$ & 45 & 51 & 55 \\
\hline Net energy potential of crop $i(\mathrm{Mcal} / \mathrm{kg})$ & 3.3 & 0.22 & 0.8 \\
\hline Digestible protein content of crop $i(\%)$ & 0.108 & 0.01 & 0.018 \\
\hline Flow rate of irrigation water required by crop $i$ in subarea $1\left[\left(\mathrm{~m}^{3} / \mathrm{s}\right) / \mathrm{ha}\right]$ & 0.032 & 0.051 & 0.043 \\
\hline Flow rate of irrigation water required by crop $i$ in subarea $2\left[\left(\mathrm{~m}^{3} / \mathrm{s}\right) / \mathrm{ha}\right]$ & 0.031 & 0.05 & 0.042 \\
\hline Flow rate of irrigation water required by crop $i$ in subarea $3\left[\left(\mathrm{~m}^{3} / \mathrm{s}\right) / \mathrm{ha}\right]$ & 0.033 & 0.052 & 0.044 \\
\hline Soil loss rate from the land planted with crop $i(\mathrm{~kg} / \mathrm{ha})$ & 5100 & 17500 & 7600 \\
\hline Unit price of crop $i(\$ / \mathrm{kg})$ & 0.45 & 0.97 & 0.72 \\
\hline Unit farming cost of crop $i(\$ / \mathrm{ha})$ & 1650 & 10500 & 2750 \\
\hline Unit cost to deliver water to $S_{i t}$ in Subarea $1\left\{\$ /\left(\mathrm{m}^{3} / \mathrm{s}\right)\right\}$ & 2450 & 2800 & 2600 \\
\hline Unit cost to deliver water to $S_{i t}$ in Subarea $2\left\{\$ /\left(\mathrm{m}^{3} / \mathrm{s}\right)\right\}$ & 4000 & 4400 & 4200 \\
\hline Unit cost to deliver water to $S_{i t}$ in Subarea $3\left\{\$ /\left(\mathrm{m}^{3} / \mathrm{s}\right)\right\}$ & 5200 & 5600 & 5400 \\
\hline \multirow{2}{*}{ Parameters related to livestock } & Cattle & Swine & Poultry \\
\hline & $j=1$ & $j=2$ & $j=3$ \\
\hline Unit manure amount generated by livestock $j$ (t/unit) & 18 & 1.8 & 0.04 \\
\hline Unit digestible protein requirement of livestock $j$ (kg/unit) & 350 & 35 & 1.8 \\
\hline Unit net energy requirement of livestock $j$ (Mcal/unit) & 5200 & 515 & 188 \\
\hline Unit average return from livestock $j$ (\$/unit) & 900 & 75 & 5.4 \\
\hline
\end{tabular}

* The related data are adapted from Huang (1996) and Nie et al. (2008).

Table 3. General Model Parameters

\begin{tabular}{|c|c|}
\hline \multicolumn{2}{|l|}{ Deterministic parameters } \\
\hline Maximum allowable total nitrogen loss rate $(\mathrm{kg} / \mathrm{ha})$ & 38 \\
\hline Nitrogen concentration of manure $(\mathrm{kg} / \mathrm{t})$ & 13 \\
\hline Nitrogen content of soil (\%) & 0.02 \\
\hline Phosphorus content of soil (\%) & 0.0009 \\
\hline Nitrogen volatilization/denitrification rate of manure (\%) & 0.3 \\
\hline Phosphorus volatilization/denitrification rate of manure (\%) & 0.1 \\
\hline Maximum loss rate of dissolved nitrogen by runoff $(\mathrm{kg} / \mathrm{ha})$ & 2.3 \\
\hline Maximum loss rate of dissolved phosphorus by runoff $(\mathrm{kg} / \mathrm{ha})$ & 0.02 \\
\hline Unit cost of fertilizer application $(\$ / \mathrm{kg})$ & 1.5 \\
\hline Unit cost of manure collection/disposal $(\$ / t)$ & 7.8 \\
\hline \multicolumn{2}{|l|}{ Fuzzy parameters } \\
\hline Maximum allowable soil loss rate $(\mathrm{kg} / \mathrm{ha})$ & $(3700,5000,6500,9000)$ \\
\hline Maximum allowable soil-phase nitrogen loss rate $(\mathrm{kg} / \mathrm{ha})$ & $\operatorname{Exp}[-|\xi-17.8| / 2.5]$ \\
\hline Maximum allowable soil-phase phosphorus loss rate (kg/ha) & $\operatorname{Exp}[-|\xi-8.2| / 1.2]$ \\
\hline Soil loss rate from the land planted with wheat $(i=1)$ & $(2600,5100,7700)^{*}$ \\
\hline Soil loss rate from the land planted with vegetable $(i=2)$ & $(9000,17500,26500)$ \\
\hline Soil loss rate from the land planted with potato $(i=3)$ & $(3870,7600,11400)$ \\
\hline
\end{tabular}




$$
I P F=\left\{\begin{array}{l}
0 \text { if } H(X, \eta) \text { is met } \\
\lambda_{2} \text { if } H(X, \eta) \text { is not met }
\end{array}\right.
$$

$$
G(X, \xi)=\left\{\begin{array}{l}
\operatorname{Pos}\left\{\tilde{L}_{i}, \tilde{b} \mid \sum_{t=1}^{T} \sum_{i=1}^{I} \tilde{L}_{i} S_{i t} \leq \tilde{b} \sum_{t=1}^{T} K_{t}\right\} \geq \alpha \\
\operatorname{Pos}\left\{\tilde{L}_{i}, \tilde{c}_{1} \mid \sum_{t=1}^{T} \sum_{i=1}^{I} h_{1} \tilde{L}_{i} S_{i t} \leq \tilde{c}_{1} \sum_{t=1}^{T} K_{t}\right\} \geq \alpha \\
\operatorname{Pos}\left\{\tilde{L}_{i}, \tilde{c}_{2} \mid \sum_{t=1}^{T} \sum_{i=1}^{I} h_{2} \tilde{L}_{i} S_{i t} \leq \tilde{c}_{2} \sum_{t=1}^{T} K_{t}\right\} \geq \alpha
\end{array}\right.
$$

$$
H(X, \eta)=\left\{\begin{array}{l}
\sum_{i=1}^{I} M_{i}-\sum_{j=1}^{J} B_{j} Z_{j}=0 \\
\left(1-p_{1}\right) g M_{i}+\left(1-p_{2}\right) F_{i}-\sum_{t=1}^{T} q_{i} S_{i t} \geq 0, \forall i \\
\sum_{t=1}^{T} \sum_{i=1}^{I} Y_{i} \beta_{i} S_{i t}-\sum_{j=1}^{J} E_{j} Z_{j} \geq 0 \\
\sum_{t=1}^{T} \sum_{i=1}^{I} Y_{i} \gamma_{i} S_{i t}-\sum_{j=1}^{J} D_{j} Z_{j} \geq 0 \\
\sum_{i=1}^{I}\left(M_{i} g+F_{i}-q_{i} \sum_{t=1}^{T} S_{i t}\right) \leq a \sum_{t=1}^{T} K_{t} \\
\sum_{i=1}^{I} S_{i t} \leq K_{t}, \forall t \\
\sum_{t=1}^{T} \sum_{i=1}^{I}\left(R_{1 i} N_{1 i}+R_{2 i} N_{2 i}\right) S_{i t} \leq u_{1} \sum_{t=1}^{T} K_{t} \\
\sum_{t=1}^{T} \sum_{i=1}^{I}\left(R_{1 i} P_{1 i}+R_{2 i} P_{2 i}\right) S_{i t} \leq u_{2} \sum_{t=1}^{T} K_{t} \\
\sum_{i=1}^{I} W_{i t} S_{i t} \leq Q_{t}, \forall t
\end{array}\right.
$$

$S_{i n t}, M_{i n}, F_{i n}, Z_{j} \geq 0, \forall i, j, n, t$

where $f=$ net system income $(\$) ; t, i$ and $j(t=1,2, \ldots, T ; i=1$, $2, \ldots, I ; j=1,2, \ldots, J)$ are indexes of subarea, crops and livestock, respectively; $T, I$ and $J$ are numbers of subarea, crops and livestock, respectively; $Y_{i}=$ unit yield of crop $i(\mathrm{~kg} / \mathrm{ha}) ; S_{i t}$ $=$ area of crop $i$ in subarea $t$ (ha); $Z_{j}=$ number of livestock $j$ in the study area; $\delta_{i}=$ unit price of crop $i(\$ / \mathrm{kg}) ; \eta_{j}=$ unit average return from livestock $j$ (\$/unit); $G_{i}=$ unit farming cost for crop $i(\$ / \mathrm{ha}) ; G_{M}=$ unit cost of manure collection and dispo$\operatorname{sal}(\$ / \mathrm{t}) ; G_{H}=$ unit cost of fertilizer application $(\$ / \mathrm{kg}) ; v_{i t}$ = unit cost to deliver water to $S_{i t}\left(\$ / \mathrm{m}^{3} / \mathrm{s}\right) ; M_{i}=$ amount of manure applied to crop $i(t) ; F_{i}=$ amount of fertilizer nitrogen applied to crop $i(\mathrm{~kg}) ; W_{i t}=$ flow rate of irrigation water required by crop $i$ in subarea $t\left(\mathrm{~m}^{3} / \mathrm{s} / \mathrm{ha}\right) ; B_{j}=$ unit amount of manure generated by livestock $j$ that needs to be disposed (t/unit); $p_{1}=$ nitrogen volatilization/denitrification rate of manure (\%); $g=$ nitrogen concentration of manure $(\mathrm{kg} / \mathrm{t}) ; p_{2}=$ nitrogen volatilization/denitrification rate of fertilizer $(\%) ; q_{i}=$ unit nitrogen requirement of crop $i(\mathrm{~kg} / \mathrm{ha}) ; \beta_{i}=$ net energy potential of crop
$i(\mathrm{Mcal} / \mathrm{kg}) ; E_{j}=$ unit net energy requirement of livestock $j$ (Mcal/unit); $\gamma_{i}=$ digestible protein content of crop $i(\%) ; D_{j}$ $=$ unit digestible protein requirement of livestock $j$ (kg/unit); $K_{t}=$ tillable area in subarea $t(\mathrm{ha}) ; L_{i}=$ soil loss rate from land planted with crop $i(\mathrm{~kg} / \mathrm{ha}) ; b=$ maximum allowable soil loss rate $(\mathrm{kg} / \mathrm{ha}) ; c_{1}=$ maximum allowable solid-phase nitrogen loss rate $(\mathrm{kg} / \mathrm{ha}) ; c_{2}=$ maximum allowable solid-phase phosphorus loss rate $(\mathrm{kg} / \mathrm{ha}) ; a=$ maximum allowable total nitrogen loss rate $(\mathrm{kg} / \mathrm{ha}) ; h_{1}=$ nitrogen content of soil $(\%) ; h_{2}=$ phosphorus content of soil (\%); $N_{1 i}=$ dissolved nitrogen concentration in wet season runoff from land planted to crop $i(\mathrm{mg} / \mathrm{l}) ; N_{2 i}=$ dissolved nitrogen concentration in dry season runoff from land planted to crop $i(\mathrm{mg} / \mathrm{l}) ; R_{1 i}=$ wet season runoff from land planted to crop i $(\mathrm{mm}) ; R_{2 i}=$ dry season runoff from land planted to crop $i(\mathrm{~mm}) ; u_{1}=$ maximum allowable loss rate of dissolved nitrogen by runoff $(\mathrm{kg} / \mathrm{ha}) ; u_{2}=$ maximum allowable loss rate of dissolved phosphorus by runoff $(\mathrm{kg} / \mathrm{ha}) ; P_{1 i}=$ dissolved phosphorus concentration in wet season runoff from land planted to crop $i(\mathrm{mg} / \mathrm{l}) ; P_{2 i}=$ dissolved phosphorus concentration in dry season runoff from land planted to crop $i(\mathrm{mg} / \mathrm{l})$; $Q_{t}=$ maximum canal flow within subarea $t(\mathrm{~m} 3 / \mathrm{s}) ; \alpha=$ prescribed confidence level.

The GAFSA model is implemented in the platform of MATLAB 2008a. The hardware settings are: (1) CPU: AMD Phenom(tm) X4 B95 Processor 3.00GHz; (2) SIMM: 4GB (D DR3 1333MHZ). The parameters of using genetic algorithm are: (1) pop sizes =100; (2) maximum generations $=2000 ;(3)$ single-point crossover rate $=0.8$; (4) the mutation rate $=0.01$; (5) termination tolerance on fitness function value $=1 \times 10^{-6}$; (6) the penalty factor for fuzzy violation $\left(\lambda_{1}\right)=2 \times 10^{6}$; (7) the penalty factor for infeasibility $\left(\lambda_{2}\right)=2 \times 10^{6}$. Generally, the average computational time of solving the agricultural water quality management model took about 50 minutes with the circle number $n=3000$.

\section{Result Analysis}

Table 4 shows the results obtained from the GAFSA model, including the system benefit and the amounts of crops, livestock, manure and fertilizer under different confidence levels. It indicates that the majority of the area in subarea 1 would be used for planting crops, while the subareas 2 and 3 would not be utilized completely and the land left over in subarea 3 would be larger. For example, under the confidence level of 0.7 , the cropping areas are determined to be 34.02, 18.56, and 32.46 ha for subareas 1 to 3 , respectively. This is mainly due to the stricter irrigation requirement on water quantity and the higher cost for delivering water in subarea 3 . From Table 4, the number of cattle and swine would be relatively lower than that of the poultry. This may be caused by multiple factors, including the related energy and protein demands, market prices and manure. It is also shown that the number of poultry would increase as the confidence level increases. For example, the number of poultry is $1912,3000,3045$, and 3728 at the confidence levels of $0.7,0.8,0.9$, and 0.95 . This is because the potato and wheat have higher energy potential and digestible protein for breeding poultry. When the confidence level increases, the cropping areas 
for both of them would increase, leading to the growth of poultry size.

Table 4. Solutions of GAFSA Model Based on GenerallyShaped Fuzzy Membership Functions of Uncertain Parameters

\begin{tabular}{llllll}
\hline \multirow{2}{*}{ Decision Variables } & \multicolumn{4}{c}{ Confidence Level } \\
\cline { 2 - 5 } & & 0.7 & 0.8 & 0.9 & 0.95 \\
\hline$S_{11}$ & Wheat & 2.28 & 3.68 & 3.72 & 4.50 \\
$S_{12}$ & Wheat & 0.01 & 2.46 & 1.52 & 1.97 \\
$S_{13}$ & Wheat & 0.70 & 1.31 & 5.47 & 5.80 \\
$S_{21}$ & Vegetable & 20.10 & 16.40 & 12.23 & 10.70 \\
$S_{22}$ & Vegetable & 15.15 & 10.60 & 7.69 & 5.44 \\
$S_{23}$ & Vegetable & 22.40 & 12.90 & 13.31 & 10.41 \\
$S_{31}$ & Potato & 11.64 & 14.00 & 18.85 & 18.89 \\
$S_{32}$ & Potato & 3.40 & 7.00 & 11.17 & 12.52 \\
$S_{33}$ & Potato & 9.36 & 20.06 & 13.65 & 14.23 \\
$Z_{1}$ & Cattle & 43 & 40 & 44 & 42 \\
$Z_{2}$ & Pig & 3 & 1 & 1 & 2 \\
$Z_{3}$ & Poultry & 1912 & 3000 & 3045 & 3728 \\
$M_{1}$ & Wheat & 0.14 & 5.06 & 49.09 & 81.43 \\
$M_{2}$ & Vegetable & 766.87 & 530.38 & 481.50 & 387.81 \\
$M_{3}$ & Potato & 82.79 & 315.94 & 386.80 & 447.81 \\
$F_{1}$ & Wheat & 352.20 & 872.54 & 910.04 & 619.66 \\
$F_{2}$ & Vegetable & 2207.30 & 1565.06 & 858.78 & 653.17 \\
$F_{3}$ & Potato & 1875.00 & 1514.78 & 949.87 & 657.90 \\
Net Income $\left(\$ 10^{5}\right)$ & 8.06 & 7.58 & 7.06 & 6.65 \\
\hline
\end{tabular}

$* i=$ type of crop; $S_{i t}=$ cropping area (ha), where $t=$ index of subarea; $M_{i}=$ applied manure amount $(t) ; F_{i}=$ amount of applied nitrogen fertilizer $(\mathrm{kg}) ; Z_{j}=$ size of livestock husbandry (unit), where $j=$ livestock.

Figure 4 shows the optimized cropping areas under various confidence levels. It is indicated that the vegetable and potato would occupy most of the areas, while the wheat would only cover a small portion. For example, under the confidence level of 0.8 , the crop areas of wheat, vegetable, and potato is 7.46 , 39.91 , and 41.06 ha, respectively. Figure 4 also shows that the cropping area would have large variations under different confidence levels. The crop area of wheat and potato under the confidence levels of 0.7 to 0.95 increases from 2.99 to 12.27 ha, and from 24.40 to 45.64 ha, respectively; while the crop area of vegetable under the confidence levels of 0.7 to 0.95 decreases from 67.65 to 26.55 ha. The decrease of crop area of vegetable is due to the fact that the vegetable has a good market price which could contribute to the net income; however, the pollution generated by the vegetable is higher than those by other crops. Conversely, the cropping areas for potato would increase when the confidence level increases, which is because, when the confidence level and system reliability become higher, the environmental loading capacities and the standard of pollutant discharge would be stricter; the system prefers to choose a crop with a relatively lower environmental impact and a higher yielding capacity (and thus a higher benefit). The potato, with moderate levels of yield, market price, and pollutant discharge, could not only contribute to the system benefit, but also satisfy the water quality requirement; it is more desirable under a stricter environmental standard.

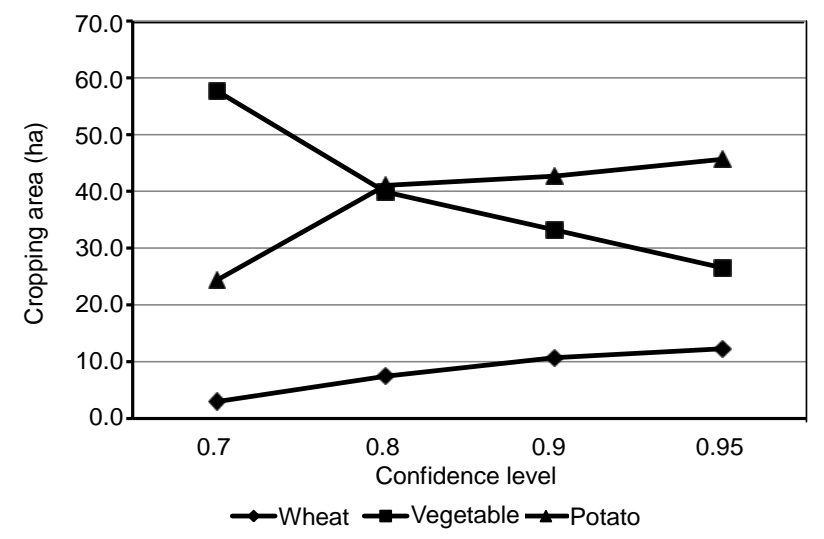

Figure 4. Optimized cropping areas under various confidence levels.

Figures 5 and 6 indicate that, with the change in the cropping areas, the manure/fertilizer requirement for the vegetable would be lower than that under a higher confidence level; while, the amount of the wheat and potato has the opposite trend. It is also found that the amount of manure is much higher than that of fertilizer by orders of magnitude. Meanwhile, with the increase of the confidence level, the total amount of fertilizer would decrease, while the total amount of manure does not have an obvious trend. The reason is that the manure and fertilizer not only provide nutrient and energy to the crops but also cause the nonpoint sources pollution problems; their usage should then be controlled to meet the environmental requirements. Manure is locally produced and related to livestock husbandry, which could contribute to the net income; while fertilizer is purchased from external sources, which is much more expensive than manure. Therefore, the total amount of fertilizer would be lower under a higher confidence level.

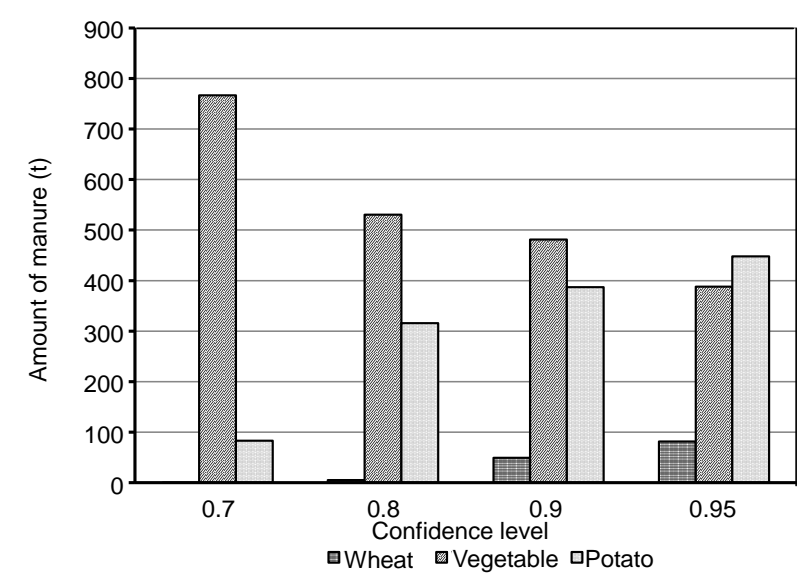

Figure 5. Applied manure amounts for different crops.

The net income of the system would decrease with the increase of the confidence level. For example, at the confidence levels of $0.7,0.8,0.9,0.95$, the net incomes would be 8.06, 
7.58, 7.06, and $6.65\left(\times 10^{5} \$\right)$, respectively. This implies that the system benefit would become higher when the environmental requirement for water quality is less strict. Thus, a conservative plan may lead to more reliable system; conversely, planning for a higher system benefit may result in a higher risk of failure.

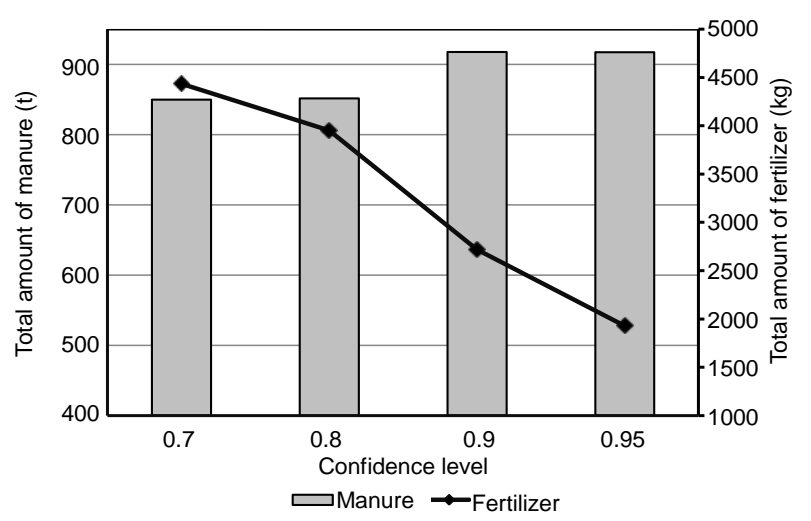

Figure 6. Optimized total manure/fertilizer amounts under various confidence levels.

Generally, the proposed GAFSA is capable of handling fuzzy parameters existing in agricultural water quality management system with generally shaped membership functions. The results obtained from GAFSA model could reflect the various trend of system benefit under different system reliabilities. The higher the system reliability, the less the net income the system would get. The results would provide useful information for water quality managers to make or select a more profitable decision at a reasonable reliability level.

The cycle index $n$ for calculating the possibility $p$ not only influences the accuracy of the model results, but also determines the time required for solving the model. Therefore, several tests were performed to search for a suitable number with lower computational requirement but acceptable accuracy. The following equation is recommended to check the relative errors using various cycle numbers:

$R E_{n}=\frac{p_{n}-p_{N}}{p_{N}} \times 100 \%$

where $p_{n}$ is the possibility calculated using $n$ cycles in fuzzy simulation and $n$ is the number of cycle index; $p_{N}$ is the possibility under a sufficiently large number of cycles (i.e. $5 \times 10^{5}$ ); $R E_{\mathrm{n}}$ is the relative error under the cycle index of $n$.

Figure 7 shows the number of cycle index vs. the accuracy of the value of possibility. Obviously, the number of cycle index would greatly infl- uence the accuracy of the value of possibility. An increase of the cycle index would lead to the reduction of relative errors. When the number of cycle index increases from 100 to 5000, the relative error would decrease from 42 to $4.5 \%$; however it would take a longer time to finish the fuzzy simulation pro- cess and thus make the GAbased optimization process more time-consuming. Therefore, a trade-off should be made between the computational requirement and simulation accuracy. It is recommended that the decision makers define an acceptable criterion for relative error (such as $5 \%$ ) before launching the fuzzy simulation.

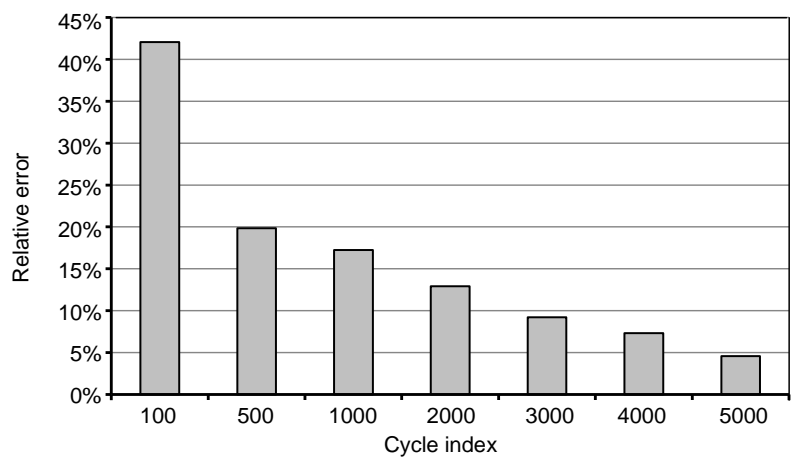

Figure 7. Relative errors under various cycle indexes.

\section{Discussion}

\subsection{Comparison with FCCP Method}

In order to demonstrate the applicability of GAFSA, we also applied the traditional FCCP method to solve the same problem. The parameters expressed as generally-shaped fuzzy sets were all replaced with triangular-shaped fuzzy sets in order to make sure the model can be solved using the algorithm proposed by Liu and Iwamura (1998). Table 5 lists the results obtained from traditional FCCP method. The table shows that the system benefits obtained from FCCP at confidence level of 0.7, 0.8, $0.9,0.95$ are $8.61,7.75,6.97$, and $6.61(\times 105 \$)$ are close to the results obtained from GAFSA. The table also shows that there exist deviations in solutions of decision variables. This is due to the fact that (i) the shapes of fuzzy distributions would influence the optimization results, and (ii) GA could only reach suboptimal solutions, especially when the number of decision variables is large. Generally, GAFSA is more advantageous than FCCP in terms of its capability in dealing with generally-shaped fuzzy variables, but inferior in its weakness of achieving less optimal solutions.

\subsection{Further Discussions on GAFSA}

(1) In real world application, the generation of membership functions is a complicated task. Some membership functions are based on the engineer's experience and are generated intuitively; others are determined by statistical techniques, such as direct rating, polling, and reverse rating (Mazloumzadeh et al., 2008). However, in our study, some parameters are considered to have specific shapes of fuzzy membership functions (such as triangular, trapezoidal, and exponential form) in order to simplify the fuzzy simulation process and better demonstrate the applicability of GAFSA.

(2) Parameters associated with environmental loading capacities (such as soil loss amounts from land planted to crop, allowable soil loss and pollutants discharge amounts) are nor- 
Table 5. Solutions from FCCP Method Based on Triangular Fuzzy Membership Functions of Uncertain Parameters

\begin{tabular}{llllll}
\hline \multirow{2}{*}{ Decision Variables } & \multicolumn{4}{c}{ Confidence Level } \\
\cline { 3 - 6 } & & 0.7 & 0.8 & 0.9 & 0.95 \\
\hline$S_{11}$ & Wheat & 0 & 0 & 0 & 0 \\
$S_{12}$ & Wheat & 0 & 0 & 0 & 0 \\
$S_{13}$ & Wheat & 0 & 0 & 0 & 0 \\
$S_{21}$ & Vegetable & 29.64 & 21.54 & 13.78 & 10.28 \\
$S_{22}$ & Vegetable & 0 & 0 & 0 & 0 \\
$S_{23}$ & Vegetable & 0 & 0 & 0 & 0 \\
$S_{31}$ & Potato & 4.46 & 12.56 & 20.32 & 23.82 \\
$S_{32}$ & Potato & 23.90 & 23.90 & 23.90 & 23.90 \\
$S_{33}$ & Potato & 2.72 & 2.89 & 3.69 & 3.93 \\
$Z_{1}$ & Cattle & 33 & 33 & 32 & 32 \\
$Z_{2}$ & Pig & 0 & 0 & 5 & 4 \\
$Z_{3}$ & Poultry & 1785 & 2059 & 2506 & 2659 \\
$M_{1}$ & Wheat & 0 & 0 & 0 & 0 \\
$M_{2}$ & Vegetable & 589.00 & 171.87 & 70.99 & 204.32 \\
$M_{3}$ & Potato & 76.40 & 504.49 & 614.25 & 485.24 \\
$F_{1}$ & Wheat & 0 & 0 & 0 & 0 \\
$F_{2}$ & Vegetable & 0 & 2220.58 & 1757.43 & 0 \\
$F_{3}$ & Potato & 2790.72 & 0 & 0 & 1532.72 \\
$N_{e}$ Income $\left(\$ 10^{5}\right)$ & 8.61 & 7.75 & 6.97 & 6.61 \\
\hline
\end{tabular}

$* i=$ type of crop; $S_{i t}=$ cropping area (ha), where $t=$ index of subarea; $M_{i}$ $=$ applied manure amount $(t) ; F_{i}=$ amount of applied nitrogen fertilizer

$(\mathrm{kg}) ; Z_{j}=$ size of livestock husbandry (unit), where $j=$ livestock.

mally estimated based on empirical experience and subject to human judgments. Hence they could be expressed by fuzzy sets with various membership functions, and other parameters are deemed as deterministic. The parameters in objective function (e.g. economical parameters) may also be subjected to uncertainties. To simplify the fuzzy simulation process for an easier demonstration, we assume these parameters are deterministic. However, in real-world applications, identifying the uncertainty of a specific parameter is not an easy task. We need to analyze them according to history record, experiment data, or survey information. If too many uncertain inputs are encountered, we can conduct a sensitive analysis first and find out the most sensitive parameters for uncertainty assessment.

(3) GA could give better optimal solution than that of conventional algorithm when the amount of decision variables is not so many. However, it is generally time-consuming to obtain convergent solutions when there are hundreds of decision variables. Also, the accuracy of solutions is also affected by local optima that cannot be easily solved by GA. Therefore, it is recommended that GA is more suitable for small scale problems. According to our study, it is suggested that the number of decision variables is better controlled within 20 . Further test is required for larger-scale applications.

(4) GA was used by Qin et al. (2010) to solve a stochastic chance constrained model. Monte Carlo simulation technique was proposed to estimate the probability of meeting the stochastic constraint and check the feasibility of potential solutions. However, Monte Carlo technique can only handle stochastic parameters. The fuzzy-simulation-based iteration process, as applied in this study, can be used to estimate the possibilistic value of fuzzy constraint satisfaction.

\section{Conclusions}

A combined genetic algorithm and fuzzy simulation approach (GAFSA) was developed in this study and applied to a study case of water quality management within an agricultural system. GAFSA incorporated genetic algorithm(GA) into a fuzzy chance-constrained programming framework, allowing some constraints with fuzzy variables to be satisfied at specified confidence levels. Moreover, with the assistance of GA, GAFSA was capable of tackling fuzzy parameters with generally shaped membership functions. The results indicated that higher confidence level would result in lower system benefit. A conservative planning scheme could bring a more reliable system, but would be less economically attractive. Conversely, planning towards a higher system benefit would lead to a higher risk of system failure. Moreover, the results could also assist agricultural water managers to make a trade-off between the overall system benefit and the failure risk of environmental compliance.

This study made a new attempt to apply the GAFSA to solve FCCP model in an agricultural water quality management system. The results implied that the integrated technique was applicable to practical problems associated with highly complex and uncertain information, and could be further applied to many other environmental problems. However, GAFSA also showed some limitations: (i) the evaluation process in GA may lead to a suboptimal solution; (ii) the solution process is timeconsuming when number of cycle index is large. Further study is needed to tackle these limitations.

Acknowledgement: This research was supported by Academic Research Fund (AcRF) Tier 1 (M4010973.030), Ministry of Education (MOE), Singapore, and DHI-NTU Water and Environment Research Centre and Education Hub.

\section{References}

Aviso, K.B., Tan, R.R., Culaba, A.B., Foo, D.C.Y., and Hallale, N. (2010). Fuzzy optimization of topologically constrained eco- industrial resource conservation networks with incomplete information. Eng. Optimiz., 43(3), 257-279. http://dx.doi.org/10.1080/0305215 X.2010.486031

Beck, M.B. (1987). Water quality modeling: A review of the analysis of uncertainty. Water Resour. Res., 23(8), 1393-1442. http://dx.doi. org/10.1029/WR023i008p01393

Cardwell, H., and Ellis, H. (1993). Stochastic dynamic programming models for water quality management. Water Resour. Res., 29(4), 803-813. http://dx.doi.org/10.1029/93WR00182

Charnes, A., and Cooper, W.W. (1959). Chance-constrained pro- gramming. Manage. Sci., 6(1), 73-79. http://dx.doi.org/10.1287/mnsc. 6.1 .73

Fan, Y.R., and Huang, G.H. (2012). A robust two-step method for solving interval linear programming problems within an environmental management context. J. Environ. Inf., 19(1), 1-9. http://dx. doi.org/10.3808/jei.201200203

Guo, P., and Huang, G. (2009). Two-stage fuzzy chance-constrained programming: Application to water resources management under dual uncertainties. Stochastic Environ. Res. Risk Assess., 23(3), 349-359. http://dx.doi.org/10.1007/s00477-008-0221-y

Haith, D.A. (1982). Environmental systems optimization, Wiley. 
Huang, G.H. (1996). Ipwm: An interval parameter water quality management model. Eng. Optimiz., 26(2), 79-103. http://dx.doi.org/ $10.1080 / 03052159608941111$

Huang, G.H., and Xia, J. (2001). Barriers to sustainable water-quality management. J. Environ. Manage., 61(1), 1-23. http://dx.doi.org/ 10.1006/jema.2000.0394

Huang, G.H., Baetz, B.W., and Patry, G.G. (1992). A gray linearprogramming approach for municipal solid-waste management planning under uncertainty. Civ. Eng. Syst., 9(4), 319-335. http://dx. doi.org/10.1080/02630259208970657

Li, Y.P., Huang, G.H., Huang, Y.F., and Zhou, H.D. (2009). A multistage fuzzy-stochastic programming model for supporting sustainable water-resources allocation and management. Environ. Model. Software, 24(7), 786-797. http://dx.doi.org/10.1016/j.envsoft.2008. 11.008

Liu, B.D., and Iwamura, K. (1998). Chance constrained programming with fuzzy parameters. Fuzzy Sets Syst., 94(2), 227-237. http://dx. doi.org/10.1016/S0165-0114(96)00236-9

Lv, Y., Huang, G.H., Li, Y.P., Yang, Z.F., Liu, Y., and Cheng, G.H (2010). Planning regional water resources system using an interval fuzzy bi-level programming method. J. Environ. Inf., 16(2), 43-56. http://dx.doi.org/10.3808/jei.201000177

Mazloumzadeh, S.M., Shamsi, M., and Nezamabadi-Pour, H. (2008). Evaluation of general-purpose lifters for the date harvest industry based on a fuzzy inference system. Comput. Electron. Agric., 60(1), 60-66. http://dx.doi.org/10.1016/j.compag.2007.06.005

Nie, X.H., Huang, G.H., Li, Y.P., and Liu, L. (2007). Ifrp: A hybrid interval-parameter fuzzy robust programming approach for waste management planning under uncertainty. J. Environ Manage., 84 (1), 1-11. http://dx.doi.org/10.1016/j.jenvman.2006.04.006

Nie, X.H., Huang, G.H., Wang, D., and Li, H.L. (2008). Robust optimisation for inexact water quality management under uncertainty. Civ. Eng. Environ. Syst., 25(2), 167-184. http://dx.doi.org/ $10.1080 / 10286600801908964$

Poojari, C.A., and Varghese, B. (2008). Genetic algorithm based tech- nique for solving chance constrained problems. Eur. J. Oper. Res., 185(3), 1128-1154. http://dx.doi.org/10.1016/j.ejor.2006.06. 045

Qin, X.S., Huang, G.H., and Liu, L. (2010). A genetic-algorithmaided stochastic optimization model for regional air quality management under uncertainty. J. Air Waste Manage. Assoc., 60(1), 6371. http://dx.doi.org/10.3155/1047-3289.60.1.63

Rehana, S., and Mujumdar, P.P. (2009). An imprecise fuzzy risk approach for water quality management of a river system. $J$. Environ. Manage., 90(11), 3653-3664. http://dx.doi.org/10.1016/j. jenvman.2009.07.007

Rong, A., and Lahdelma, R. (2008). Fuzzy chance constrained linear programming model for optimizing the scrap charge in steel production. Eur. J. Oper. Res., 186(3), 953-964. http://dx.doi.org/10. 1016/j.ejor.2007.02.017

Singh, T.S., and Chakrabarty, D. (2011). Chance-constrained multiobjective programming for optimal multi-layer aquifer remediation design. Eng. Optimiz., 43(4), 417-432. http://dx.doi.org/10.1080/ 0305215X.2010.491548

Tisdale, S.L., and Nelson, W.L. (1966). Soil fertility and fertilizers. Soil Sci., 101(4), 346. http://dx.doi.org/10.1097/00010694-196604 000-00016

Wagner, B.J., and Gorelick, S.M. (1987). Optimal groundwater quality management under parameter uncertainty. Water Res. Res., 23(7), 1162-1174. http://dx.doi.org/10.1029/WR023i007p01162

$\mathrm{Xu}$, Y., and Qin, X.S. (2010). Agricultural effluent control under uncertainty: An inexact double-sided fuzzy chance-constrained model. Adv. Water Resour., 33(9), 997-1014. http://dx.doi.org/10. 1016/j.advwatres.2010.06.002

Zadeh, L.A. (1978). Fuzzy sets as a basis for a theory of possibility. Fuzzy Sets Syst., 1(1), 3-28. http://dx.doi.org/10.1016/0165-0114 (78) $90029-5$

Zhang, X.D., Huang, G.H., and Nie, X.H. (2009). Robust stochastic fuzzy possibilistic programming for environmental decision making under uncertainty. Sci. Total Environ., 408(2), 192-201. http:// dx.doi.org/10.1016/j.scitotenv.2009.09.050 